\title{
A Multi-criteria Decision-making Model for Evaluating Suppliers in Green SCM
}

\author{
W. Jiang, C. Huang
}

\author{
Wen Jiang*, Chan Huang \\ School of Electronics and Information, \\ Northwestern Polytechnical University \\ Xi'an, Shaanxi Province, 710072, China \\ *Corresponding author: jiangwen@nwpu.edu.cn \\ huangchan@mail.nwpu.edu.cn
}

\begin{abstract}
In order to develop recycle economy and friendly saving environment, many business enterprises have deployed green supply chain management (GSCM) practices. By employing related theorise of GSCM, organizations expect to minimize the environment impact caused by their commercial and industrial activities in supply chain. Different suppliers may provide different GSCM practices, so evaluating their GSCM performance to rank the green suppliers is an important aspect in practice. In this paper, a novel decision method named fuzzy generalized regret decision-making method is proposed. The fuzzy generalized regret decision-making method is based on ordered weighted averaging (OWA) operator, which is used to effectively aggregate individual regrets related to all stats of nature for an alternative under fuzzy decision-making environment. By combing the proposed method with the application background of GSCM practices, a novel fuzzy decision model for evaluating GSCM performance is further proposed. In the proposed model, the regret of decision maker is taken into consideration with an aim of minimizing the dissatisfaction when choosing the best green supplier. Individual regrets related to all criteria for a green supplier are aggregated to obtain effective regret. Finally, the green suppliers can be ranked according to the effective regrets. A numerical example is used to illustrate the effectiveness of the proposed method.

Keywords: generalized regret decision making; green supply chain; multi-criteria decision making; fuzzy set theory.
\end{abstract}

\section{Introduction}

As the awareness of environment protection is increasing and the concerning regulations from government become more strict, green supply chain management (GSCM) plays more and more important role nowadays $[2,7,17]$. GSCM is widely used particularly in commercial and industrial applications all over the world $[1,20,37]$. The main purpose of using GSCM is to avoid the negative effects on the environment caused by the commercial and industrial activities $[31,59]$. A lot of companies have adopted concerning theory of GSCM in order to reduce the environmental and legal risk during the supply chain and enhance international competitiveness [6].

When applying GSCM practices, it is very necessary for companies to evaluate their own GSCM performance. Besides, some companies also need to green their supply chains by selecting the better supplier from the existing green suppliers $[25,26]$. Therefore, an effective tool for evaluating GSCM performance is vital in practice [22,30,40]. Many factors should be taken into consideration during the green supply chain, such as production, material, transformation, storage, purchasing, after-sales service and so on $[3,5,28,50,60]$. It is common that information is related to multiple aspects in many applications $[9,23,51]$. Actually, evaluating and selecting suppliers is a multi-criteria decision making problem $[18,48]$. It is usually inevitable that information contains some uncertainty when the suppliers are evaluated by human judge. Therefore the 
environment is fuzzy for majority of multi-criteria decision making problems in practice. Many multi-criteria decision making methods have developed in fuzzy environment [21,24,39]. Among these methods, AHP(Analytical Hierarchy Process) and TOPSIS (Technique for Order of Preference by Similarity to Ideal Solution) method are the most popular $[21,38]$. Besides, many other theories are developed and applied to supplier evaluation and selection, such as ANP(Analytic Network Process), VIKOR(VlseKriterijumska Optimizacija I Kompromisno Resenje), DEMATEL(D ecision-making Trial and Evaluation Laboratory), PROMETHEE(Preference ranking organisation method for enrichment of evaluations), COPRAS(Complex Proportional Assessment) and so on. For instance, in [20] when rating and selecting of potential suppliers, economics (cost), operational factors (quality and delivery), and environmental criteria, recycle capability and GHG emission control are considered by using Fuzzy TOPSIS method. Later the PROMETHEE method is proposed to rank the suppliers according to each decision maker's preferences in [20]. In [40] the multiple criteria evaluation method for green supply programs is based on integrating rough set theory elements and fuzzy TOPSIS. Literature [49] introduces a new decision framework to evaluate GSCM practices by combining Monte Carlo simulation, AHP and VIKOR methods under fuzzy environment. However, few work pay attention to apply regret theory to solve the problem of evaluating green supplier's performance in green supply chain.

The regret decision theory is developed by Loomes and Sugden [42], Bell [4] and Fishburn [19]. For a basic regret decision-making model, there are several different regrets for an alternative under different states of nature. The received payoffs exist some difference when decision makers choosing different alternatives under each state of nature. The regret value is defined as a reflection of the difference between the payoff from the choice of alternative and the best payoff from another choice of alternative under the same state of nature. Different from the classic decision making theory, the basic point of regret decision making is trying to minimize the dissatisfaction when not making the best decision. By applying the regret decision theory, the decision maker can choose the alternative that bringing the minimum regret. Therefore the dissatisfaction of decision maker is minimum if the alternative with the minimum regret is carried out. In this sense, the alternative with the minimum regret is the best choice, which is the most reliable one and can bringing the best payoff compared other alternatives. Naturally, the aim is to find the alternative with the minimum regret in regret decision-making model. So it is a key step to find an exact regret associated with all states of nature for each alternative. However, the regret aggregation method has some limitations in basic regret decision-making theory. For this reason, Yager proposed the generalized regret decision-making method based on OWA operator [55]. This method provides a parameterized family of operations, which can be used to more effectively aggregate an alternative's individual regrets than the basic regret decision theory [55]. However Yager's method is designed for certain decision environment and cannot settle the problem in fuzzy environment. In practice, the information obtained often is uncertain $[10,13,19]$. Many decision-making problems are under uncertain environment $[8,10,36,39]$. In these cases, the method proposed by Yager is not applicable even though this method is an effective tool to handle multi-decision making problem.

The main contribution of this paper is summarized as follows. First, a new fuzzy multiple criteria decision-making method based on regret theory is proposed. Extended the Yager's generalized decision-making method, the proposed method, called fuzzy generalized decision-making method, can effectively handle the decision making problems in fuzzy environment. Second, the proposed method is combined with the application background of GSCM practices, a novel multi-criteria decision-making model for evaluating the green supplier's performance is further proposed. By aggregating the individual regrets associated to a supplier, the effective regret can be obtained. The effective regret of a green supplier is smaller, and the decision makers 
are more satisfied with the decision of choosing this supplier. Our aim is to select the supplier with the minimum effective regret, which is the best supplier. According to all effective regrets obtained, suppliers can be ranked. A numerical example is used to illustrate the effectiveness of the proposed decision model.

The rest of this paper is organized as follows. Section 2 shows the basic concepts, including fuzzy set theory, OWA operator and presented regret type decision making. In Section 3, the proposed decision-making method and decision model for suppliers evaluation are introduced in detail. Section 4 presents a numerical application to illustrate the effectiveness of the proposed model. In the end, conclusion and the future works are shown in Section 5.

\section{Preliminaries}

\subsection{Fuzzy set theory}

The fuzzy set theory proposed by Zadeh [58] is widely applied in many fields. Nowadays many studies are related to the fuzzy set theory, such as intelligent event process [43,52,57], evidence theory $[7,9,33,34]$, aggregation operator $[49,56,74]$, decision making $[27,76]$ and so on $[16,63]$. Let $X$ be the universe of discourse, $X=\left\{x_{1}, x_{2}, \cdots, x_{n}\right\}$, a fuzzy set $\tilde{A}$ defined on $X$ is characterized by a membership function $\mu_{\tilde{A}}(x)$, which can be denoted as: $\tilde{A}=\left\{\left\langle x, \mu_{\tilde{A}}(x)\right\rangle \mid x \in X\right\}, \mu_{\tilde{A}}(x) \rightarrow$ $[0,1] . \mu_{\tilde{A}}(x)$ indicates the degree of $x \in X$ in $\tilde{A}$.

Triangular fuzzy number is a special type of fuzzy sets, $\mu_{A}(x)$ for a triangular fuzzy number $A=(a, b, c)$ is defined as following:

$$
\mu_{A}(x)=\left\{\begin{array}{cc}
0, & x<a \\
\frac{x-a}{b-a}, & x<a, x<c, a \leq x \leq b \\
\frac{c-x}{c-b}, & b \leq x \leq c \\
0, & x>c
\end{array}\right.
$$

Let $A=\left(a_{1}, b_{1}, c_{1}\right)$ and $B=\left(a_{2}, b_{2}, c_{2}\right)$ be two triangular fuzzy numbers. Some basic arithmetic operations for triangular fuzzy numbers are given as follows [41]:

$$
\begin{gathered}
A+B=\left(a_{1}, b_{1}, c_{1}\right)+\left(a_{2}, b_{2}, c_{2}\right)=\left(a_{1}+a_{2}, b_{1}+b_{2}, c_{1}+c_{2}\right) \\
A-B=\left(a_{1}, b_{1}, c_{1}\right)+\left(a_{2}, b_{2}, c_{2}\right)=\left(a_{1}-a_{2}, b_{1}-b_{2}, c_{1}-c_{2}\right) \\
\lambda A=\left(\lambda a_{1}, \lambda b_{1}, \lambda c_{1}\right)
\end{gathered}
$$

where $\lambda$ is a real number.

The distance between two triangular fuzzy numbers is a basic concept for triangular fuzzy number. There are many methods for calculating the distance. One popular and classical distance function is defined as follows [15]:

$$
d(A, B)=\sqrt{\left[\left(a_{1}-a_{2}\right)^{2}+\left(b_{1}-b_{2}\right)^{2}+\left(c_{1}-c_{2}\right)^{2}\right]}
$$

The similarity of two triangular fuzzy numbers $A$ and $B$ can be defined as [29]:

$$
s(A, B)=1-\frac{\left|a_{1}-a_{2}\right|+\left|b_{1}-b_{2}\right|+\left|c_{1}-c_{2}\right|}{3}
$$

Obviously, the value of $s(A, B)$ is larger, the two triangular fuzzy numbers $A$ and $B$ are more similar. 


\subsection{Ordered weighted averaging (OWA) operator}

Averaging operator proposed by Yager is a important tool for information fusion $[46,57]$. An OWA operator of dimension $m$ is a mapping OWA: $R^{m} \rightarrow R$ that has an associated $m$ dimensional weighting vector $w=\left(w_{1}, w_{2}, \cdots w_{m}\right)$. If $j=1, \cdots, m$ the $y_{j}$ are a collection of numeric values. Then the OWA aggregation of these value is

$$
O W A\left(y_{1}, y_{2}, \cdots, y_{m}\right)=\sum_{k=1}^{m} w_{k} y_{\rho(k)}
$$

where $w_{k} \in[0,1]$ and $\sum_{k=1}^{m} w_{k}=1 . \rho(k)$ is the index of the $k$ th largest of $y_{j}$.

A number of approaches have been introduced to obtain the OWA weights [47]. In [56] Yager introduced a functional method of obtaining $w_{k}$ from function $f:[0,1] \rightarrow[0,1]$ :

$$
w_{k}=f\left(\frac{k}{n}\right)-f\left(\frac{k-1}{n}\right), \quad k=1,2, \cdots, n
$$

where function $f$ satisfies $f(x) \geq f(y)$ if $x>y$, and $f(0)=0$ and $f(1)=1$.

\subsection{Generalized regret decision-making theory}

For a decision-making problem, assume there are $m$ possible states of nature and $n$ alternatives, then this problem can be shown as following in a matrix $S=\left[s_{i j}\right]_{m \times n}$, where $s_{i j}$ is the payoff received from the result of decision about $j$ th alternative under $i$ th state of nature. According to the basic regret decision making theory, the decision of selecting an alternative should meet the desire that the regret of this choice is minimum $[4,42]$. For this point, the regret matrix $V$ is $R=\left[r_{i j}\right]_{m \times n}$, where $r_{i j}=s_{i \max }-s_{i j}$ represents the difference between the payoff $s_{i \max }$ received from the $j$ th alternative and the maximal payoff $s_{i j}$ received from another alternative under $i$ th state of nature. The regret $R_{j}=A g g_{i=1}$ to $m\left[r_{i j}\right]$ for each alternative is calculated and then select the alternative with minimum regret $R^{\prime}=\operatorname{Minn}_{j=1}$ to $n\left[R_{j}\right]$.

In the framework of generalized regret type decision-making based on OWA, the equation of calculating aggregated regret $R_{j}$ is defined as [55]:

$$
R_{j}=O W A\left(r_{1 j}, r_{2 j}, \cdots, r_{m j}\right)=\sum_{k=1}^{m} w_{k} r_{j p_{j}(k)}
$$

One condition is that a smaller regret is assigned no more weight than a bigger regret. That is if $r_{i \rho_{i}\left(k_{1}\right)}>r_{i \rho_{i}\left(k_{2}\right)}$ then $w_{k_{1}}>w_{k_{2}}$, which ensures a greater regret to dominate among all individual regrets for an alternative. The OWA weights of regrets can be obtained by Eq. (8), in which one feasible function $f$ is $f(x)=x^{r}$, and $r \in(0,1)$ [55]. So the equal for obtaining OWA weights of regrets is shown as follows [55]:

$$
R_{j}=\sum_{k=1}^{m} w_{k} r_{j p_{j}(k)}=\sum_{k=1}^{m}\left(\left(\frac{k}{m}\right)^{r}-\left(\frac{k-1}{m}\right)^{r}\right) r_{j p_{j}(k)}
$$

\section{The proposed method and model for GSCM practices}

\subsection{The proposed fuzzy generalized regret decision-making method}

The generalized regret decision-making method proposed by Yager is an effective decision making-method and overcomes the limitations of the basic regret decision making method. However this method is designed for exact number and can not be applied for fuzzy environment. As we all know many decision-making problems are presented in the fuzzy environment in practice. For this issue, a fuzzy generalized regret decision making method is proposed in this paper. The 


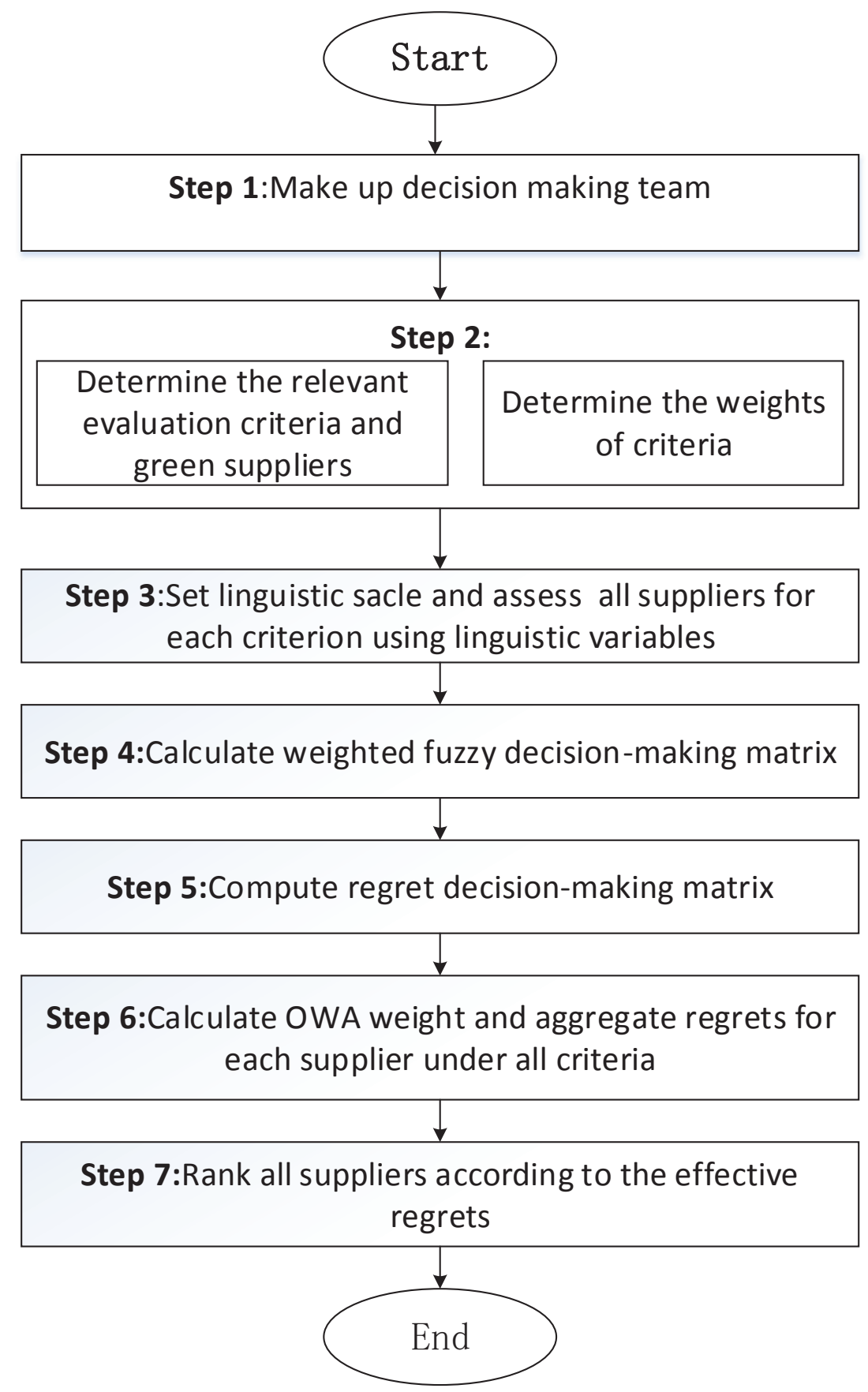

Figure 1: The proposed model for ranking green suppliers in GSCM practice 
proposed method extends Yager's generalized regret decision making method to the fuzzy environment and this can be used to effectively handle fuzzy decision making problem. The proposed fuzzy generalized regret decision-making method consists of the following steps:

Step 1: For a decision making problem assume $C_{i}$ for $i=1$ to $m$ is the state of nature ,the existing alternative is $A_{j}$ for $i=1$ to $n$. And the weight of the states of nature should be taken into consideration, which is expressed by triangular fuzzy number and is called the fuzzy weight in this paper. Then matrix can be indicated as:

$$
S=\left[\begin{array}{cccc}
s_{11} & s_{12} & \cdots & s_{1 n} \\
s_{21} & s_{22} & \cdots & s_{2 n} \\
\vdots & \vdots & \ddots & \vdots \\
s_{m 1} & s_{m 2} & \cdots & s_{m n}
\end{array}\right]
$$

where $s_{i j}=\left(a_{i j}, b_{i j}, c_{i j}\right)$, which is a triangular fuzzy number, represents the payoff for alternative $j$ under state of nature $i$.

Step 2: The fuzzy weight of each states of nature is transformed to crisp number, then the matrix multiplied by defuzzified weights of the decision criteria is transformed to weighted fuzzy-decision matrix:

$$
V=\left[\begin{array}{cccc}
v_{11} & v_{12} & \cdots & v_{1 n} \\
v_{21} & v_{22} & \cdots & v_{2 n} \\
\vdots & \vdots & \ddots & \vdots \\
v_{m 1} & v_{m 2} & \cdots & v_{m n}
\end{array}\right]
$$

where $v_{i j}=v_{i j} \cdot w_{i}$ and $w_{i}$ is the defuzzified weight of the $i$ th state of nature.

Step 3: In this step the regret matrix is expected to get from the weighted fuzzy-decision matrix. Assume $v_{i \max }$ is the maximum fuzzy number of $i$ th row matrix.

First the maximum $v_{i \max }$ under the state of nature $C_{i}$ is obtained by sorting the triangular fuzzy numbers of $i$ th row of matrix $V$. According to the regret theory, the regret value $r_{i j}$ is represented by the difference between matrix element $v_{i j}$ and the maximum $v_{i \max }$. A difference measure dif is given based on the similarity of two triangular fuzzy numbers in this paper and is defined as:

$$
\operatorname{dif}\left(v_{i j}, v_{i \max }\right)=1-s\left(v_{i j}, v_{i \max }\right)
$$

Obviously the value of $\operatorname{dif}\left(v_{i j}, v_{j \max }\right)$ is larger, the difference degree between two triangular fuzzy numbers $v_{i j}$ and $v_{i \max }$ is bigger. Based on the difference measure dif, the regret matrix $R$ is obtained as:

$$
R=\left[r_{i j}\right]_{m \cdot n}, \quad i=1,2, \cdots, m ; j=1,, 2, \cdots, n
$$

where $r_{i j}=\operatorname{dif}\left(v_{i j}, v_{j \max }\right)$.

Step 4: Since the regret matrix elements obtained though the last step are crisp numbers, thus the effective regret of each alternative can be calculated by Eq. (9).

Step 5: Finally all the alternatives should be ranked according to the effective regrets obtained in the step 4. The effective regret value is smaller indicating the corresponding alternative is better. Among all alternatives the best one is the one with the minimum effective regret.

\subsection{The decision model for GSCM practice}

The aim of using GSCM practices is developing friendly environment and reduce the adverse effects on the environment. It is important to evaluate suppliers according to their comprehensive performance about GSCM's criteria. In this part, based on the proposed fuzzy generalized regret decision-making method, a new decision model is proposed to evaluate the green supplier's 
performance in GSCM. When using the proposed model evaluates the performance of suppliers, different criteria can be seen as different states of nature and green suppliers are equivalent to alternatives. Assessments made by experts reflect the performance of green suppliers under different criteria. The assessment matrix is the decision-making fuzzy matrix in the proposed method. The process of ranking green suppliers with the proposed model is shown in Figure 1 and indicated as follows.

Step 1: The environmental experts are selected to form a decision-making team.

Step 2: Experts determine the relevant criteria for selecting and evaluating green suppliers. Then the weights of all criteria are given by experts according to the importance of each criterion.

Step 3: Set the appropriate linguistic scale for green suppliers related to criteria for alternatives. Those linguistic scale is used to evaluate all green suppliers under each criterion by environmental experts. Then those linguistic scale are transformed to scale with fuzzy numbers, which is used to transform the linguistic assessments to the assessment matrix expressed by fuzzy number.

Step 4: According to the weights of each criterion, the assessment matrix are disposed to get the weighted fuzzy assessment matrix. First assessments from different experts for each criterion should be fused into one fuzzy number so that fused assessment matrix is obtained. In addition, the weights of criteria with fuzzy number is transformed to crisp number. Then the weighted fuzzy assessment matrix $V$ is obtained by multiplying the defuzzified weight and fused assessment matrix.

Step 5: The regret decision-making matrix is calculated according to weighted fuzzy assessment matrix $V$. First by ranking the triangular fuzzy numbers, the maximal fuzzy number $v_{i \max }$ is selected from $i$ th row of weighted fuzzy assessment matrix $V$. Then based on matrix $V$ and $v_{i \max }$ for $i=1$ to $i=m$, the regret decision-making matrix $R$ is obtained by Eq. (6).

Step 6: OWA weight is calculated by Eq. (10) and individual regrets under each criteria for each green suppliers are aggregated in this step. In order to aggregate the regrets based on OWA operator, each column elements in matrix $R$ is sorted in descending order to get $r_{j p_{j}(k)}$. Then Eq. (7) is used to aggregate all individual regrets under each criteria for each supplier to obtain effective regrets.

Step 7: Alternative suppliers can be ranked according to the effective regrets. The alternative with smaller effective regret, then it ranks higher.

\section{An illustrative application and discussing}

In this section, a numerical example from [49] is used to show the proposed decision model in detail and illustrate its effectiveness. It is considered that a manufacture employs GSCM practices and needs to evaluate four green suppliers according to their performance in GSCM. And the managers of this manufacture make use of our proposed decision model to make this evaluation.

First, the basic example data in [49] is given. The criteria for evaluating four suppliers is shown in Table 1. Those criteria are divided into four groups, which is inbound,operations,production operations, outbound operations, and reverse logistics and four suppliers. Each criterion group consists of several sub-criteria. Globe fuzzy weights of all criteria based on the importance of each criterion and linguistic assessments of three experts are presented in Table 3. In addition, linguistic scale is shown in Table 4.

Then the assessment matrix is disposed to get the weighted fuzzy assessment matrix. Assessments of three experts can be fussed by equal because there is no weight information about these experts. Let $A=\left(a_{1}, b_{1}, c_{1}\right), B=\left(a_{2}, b_{2}, c_{2}\right), C=\left(a_{3}, b_{3}, c_{3}\right)$ be the assessments given by three experts, then those three assessments can be fused by $D=\frac{1}{3} \times(A+B+C)$. The fused 
assessments matrix $S$ is shown in Table 4. The fused assessments matrix is weighted to ensure that can reflect the importance degree of criteria. The weights of criteria can be transformed to the crisp number first. The weight $\tilde{W}=\left(w_{1}, w_{2}, w_{3}\right)$ of each criterion is defuzzified by using following function:

$$
W=\frac{\left(w_{1}+4 w_{2}+w_{3}\right)}{6}
$$

After defuzzfying, the fuzzy weights are transformed to crisp numbers. By multiplying the defuzzified weight and fussing assessment matrix, the crisp weights and a weighted fuzzy assessment matrix $V$ are shown in Table 5 .

The next step is to calculate the regret decision-making matrix according to weighted fuzzy assessment matrix $V$. First, all triangular fuzzy numbers need to be ranked to find the the maximal fuzzy number $v_{i \max }$. It can be seen that any two triangular fuzzy numbers $V_{1}=$ $\left(a_{1}, b_{1}, c_{1}\right)$ and $V_{2}=\left(a_{2}, b_{2}, c_{2}\right)$ of case in [49] always satisfy $b_{1}>b_{2}$ and $c_{1}>c_{2}$ if $a_{1}>a_{2}$. Distance between two triangular fuzzy numbers defined in Section 2, which is commonly applied to rank triangular fuzzy number. The value of distance can be calculated by Eq. ( 5 in this example. It is noted that the best assessment given by expert is VG with triangular fuzzy scale $(7,9,10)$. Let $L=(7,9,10), v_{i \max }=\operatorname{Max}\left[v_{i j}\right]$. Thus the distance between $L$ and $v_{i \max }$ is minimum among all elements in row $i$. It can be seen that any two triangular fuzzy numbers $V_{1}=\left(a_{1}, b_{1}, c_{1}\right)$ and $V_{2}=\left(a_{2}, b_{2}, c_{2}\right)$ of case in [49] always satisfy $b_{1}>b_{2}$ and $c_{1}>c_{2}$ if $a_{1}>a_{2}$. Eq. (13) is used to calculate distance between $L$ and $v_{i j}$ so that we can find $v_{i \text { max }}$ according to the minimum value of distance. The result of largest fuzzy numbers of each row is showed in Table 5. Based on the data in Table 5, the fusing regret matrix $R$ shown in Table 6 is obtained by Eq. (6).

At this stage, each column elements in matrix $R$ are sorted in descending in order to get $r_{j p_{j}(k)}$. The effective regrets for four suppliers can be obtained by Eq. (10). Same as the case for calculating effective regrets in literature [55], $r$ in Eq. (10) takes 0.5 in this case. And there are 18 criteria, so $m$ in Eq.(10) is 18. OWA weights $W_{k}$ and $r_{j p_{j}(k)}$ is shown in Table 7 .

After obtaining the effective regrets, the alternative suppliers can be ranked. The greater regret for a supplier, the higher the ranking. Finally, alternative suppliers can be ranked according to the effective regrets. The result of effective regrets and the both ranking result obtained by proposed model and by the method in [49] are presented in Table 8. According to the ranking result shown in Table 8, supplier D ranks number 1, which shows that the performance of supplier $\mathrm{D}$ is the best among four suppliers. Therefore, the decision of this GSCM problem is choosing supplier D to support GSCM practice for this manufacture.

By comparing two ranking results shown in Table 8, it can be seen that both two results support that: (1) supplier A and supplier D rank higher than supplier B and supplier C, that is to say, the performance of supplier A and supplier D are better than supplier B and supplier C; (2) supplier C rank higher than supplier D, that is, supplier C is better than supplier B. The difference of two ranking results is the ordering of supplier A and supplier D. The ranking result obtained by the proposed method shows the supplier D rank higher than supplier A. However, the result obtained by method in [49] shows that supplier A and supplier D both rank number one.

In [49] supplier A and supplier D both rank number one, which means there is no difference between good or bad for supplier A and supplier D. So in practice it is difficult for managers to make a choice between supplier A and supplier D. However, the proposed method overcomes this shortcoming. According to Table 8, it is known that the effective regrets of supplier A and supplier D are much lager than supplier B and supplier C and the regret of supplier A is lager than supplier D. This result indicates that supplier A and supplier D are better alternatives for 
Table 1: Criteria for evaluating GSCM [49]

\begin{tabular}{ccc}
\hline The group of the criteria & Criteria & Concrete content of criteria \\
\hline \multirow{4}{*}{ inbound operations } & $\mathrm{C} 1.1$ & Choosing suppliers by environmental criteria \\
& $\mathrm{C} 1.2$ & Guiding suppliers to establish their own environmental programs \\
& $\mathrm{C} 1.4$ & Urging/pressuring suppliers to take environmental actions \\
& $\mathrm{C} 2.1$ & Purchasing environment friendly items \\
\hline \multirow{5}{*}{ production operations } & $\mathrm{C} 2.2$ & Design products for recycling \\
& $\mathrm{C} 2.3$ & Using cleaner technology \\
& $\mathrm{C} 2.4$ & Improving capacity utilization \\
& $\mathrm{C} 3.1$ & Promoting remanufacturing \\
\hline \multirow{5}{*}{ outbound operations } & $\mathrm{C} 3.2$ & Enhancing vehicle operating efficiency \\
& $\mathrm{C} 3.3$ & Encouraging eco-driving \\
& $\mathrm{C} 3.4$ & Using environmental friendly packaging \\
& $\mathrm{C} 3.5$ & Reducing empty running \\
& $\mathrm{C} 3.6$ & Improving vehicle routing using GPS (Global Positioning System) and other systems \\
reverse logistics & Increasing vehicle payload capacity \\
& $\mathrm{C} 4.1$ & Re-use of products and components \\
& $\mathrm{C} 4.2$ & Recycling of materials \\
& $\mathrm{C} 4.4$ & Waste management \\
& & Taking back packaging \\
\hline
\end{tabular}

Table 2: Linguistic assessments of suppliers and Weights of criteria [49]

\begin{tabular}{cccccc}
\hline Criteria & Supplier A & Supplier B & Supplier C & Supplier D & Weight \\
\hline C1.1 & VG, G, G & F, G, P & F, G, G & G, VG, F & $(0.03,0.05,0.08)$ \\
C1.2 & G, F, P & VG, G, G & G, F, F & VG, VG, G & $(0.03,0.05,0.08)$ \\
C1.3 & P, F, F & F, P, G & P, F, VP & G, F, VG & $(0.04,0.07,0.12)$ \\
C1.4 & F, G, G & F, G, P & G, F, VG & F, VG, F & $(0.01,0.02,0.04)$ \\
C2.1 & F, P, P & F, G, F & F, G, F & VG, G, G & $(0.03,0.05,0.09)$ \\
C2.2 & F, G, F & G, VG, VG & F, F, G & VG, G, VG & $(0.03,0.06,0.10)$ \\
C2.3 & VG, G, VG & P, F, P & F, G, G & VG, G, VG & $(0.05,0.09,0.16)$ \\
C2.4 & G, VG, VG & P, P, F & F, P,P & P, G, F & $(0.02,0.04,0.07)$ \\
C3.1 & VG, G, G & G, P, G & F, G, F & VG, F, G & $(0.03,0.06,0.10)$ \\
C3.2 & VG, G, G & F, P, G & G, VG, VG & F, G, G & $(0.04,0.07,0.11)$ \\
C3.3 & VG, G, VG & G, F, P & F, G, F & VG, G, G & $(0.05,0.11,0.20)$ \\
C3.4 & G, F, VG & P, F, F & F, G, G & VG, VG, VG & $(0.03,0.05,0.09)$ \\
C3.5 & G, F, F & P, VP, VP & F, G, F & P, VP, F & $(0.04,0.06,0.10)$ \\
C3.6 & VG, G, G & F, P, F & P, VP, VP & G, VG, G & $(0.04,0.07,0.12)$ \\
C4.1 & G, VG, VG & F, G, G & G, VG, F & F, P, G & $(0.02,0.03,0.06)$ \\
C4.2 & VG, G, VG & P, F, VP & F, F, G & VG, G, G & $(0.02,0.04,0.08)$ \\
C4.3 & F, G, G & F, P, G & G, VG, F & F, P, F & $(0.03,0.06,0.11)$ \\
C4.4 & VP, P, P & F, F, G & F, G, G & VG, G, G & $(0.02,0.03,0.05)$ \\
\hline
\end{tabular}

Table 3: Linguistic scale for evaluating GSCM performance of suppliers [49]

\begin{tabular}{lc}
\hline Linguistic scale for evaluating suppliers & Triangular fuzzy scale \\
\hline Very Poor (VP) & $(0,1,3)$ \\
Poor (P) & $(1,3,5)$ \\
Fair (F) & $(3,5,7)$ \\
Good (G) & $(5,7,9)$ \\
Very Good (VG) & $(7,9,10)$ \\
\hline
\end{tabular}


Table 4: The fused assessments matrix [49]

\begin{tabular}{lllll}
\hline Criteria & \multicolumn{1}{c}{ Supplier A } & \multicolumn{1}{c}{ Supplier B } & \multicolumn{1}{c}{ Supplier C } & \multicolumn{1}{c}{ Supplier D } \\
\hline C1.1 & $(5.667,7.667,9.333)$ & $(2.333,4.333,6.333)$ & $(4.333,6.333,8.333)$ & $(5.000,7.000,8.667)$ \\
C1.2 & $(3,5,7)$ & $(5.667,7.667,9.333)$ & $(3.667,5.667,7.667)$ & $(6.333,8.333,9.667)$ \\
C1.3 & $(2.333,4.333,6.333)$ & $(3,5,7)$ & $(1.333,3.000,5.000)$ & $(5.000,7.000,8.667)$ \\
C1.4 & $(4.333,6.333,8.333)$ & $(3,5,7)$ & $(5.000,7.000,8.667)$ & $(4.3333,6.3333,8.0000)$ \\
C2.1 & $(1.667,3.667,5.667)$ & $(3.667,5.667,7.667)$ & $(3.667,5.667,7.667)$ & $(5.667,7.667,9.333)$ \\
C2.2 & $(3.667,5.667,7.667)$ & $(6.333,8.333,9.667)$ & $(3.667,5.667,7.667)$ & $(6.333,8.333,9.667)$ \\
C2.3 & $(6.333,8.333,9.667)$ & $(1.667,3.667,5.667)$ & $(4.333,6.333,8.333)$ & $(6.333,8.333,9.667)$ \\
C2.4 & $(6.333,8.333,9.6667)$ & $(1.667,3.667,5.667)$ & $(1.667,3.667,5.667)$ & $(3,5,7)$ \\
C3.1 & $(5.667,7.667,9.333)$ & $(3.667,5.667,7.667)$ & $(3.667,5.667,7.667)$ & $(5.000,7.000,8.667)$ \\
C3.2 & $(5.667,7.667,9.333)$ & $(3,5,7)$ & $(6.333,8.333,9.667)$ & $(4.3333,6.3333,8.3333)$ \\
C3.3 & $(6.333,8.333,9.667)$ & $(3,5,7)$ & $(3.667,5.667,7.667)$ & $(5.667,7.667,9.333)$ \\
C3.4 & $(5.000,7.000,8.667)$ & $(2.333,4.333,6.333)$ & $(4.333,6.333,8.333)$ & $(7,9,10)$ \\
C3.5 & $(3.667,5.667,7.667)$ & $(0.333,1.667,3.667)$ & $(3.667,5.667,7.667)$ & $(1.333,3.000,5.000)$ \\
C3.6 & $(5.667,7.667,9.333)$ & $(2.333,4.333,6.333)$ & $(0.333,1.667,3.667)$ & $(5.6667,7.6667,9.3333)$ \\
C4.1 & $(6.333,8.333,9.667)$ & $(4.333,6.333,8.333)$ & $(5.000,7.000,8.667)$ & $(3,5,7)$ \\
C4.2 & $(6.333,8.333,9.667)$ & $(1.333,3.000,5.000)$ & $(3.667,5.667,7.667)$ & $(5.667,7.667,9.333)$ \\
C4.3 & $(4.333,6.333,8.333)$ & $(3,5,7)$ & $(5.000,7.000,8.667)$ & $(2.333,4.333,6.333)$ \\
C4.4 & $(0.667,2.333,4.333)$ & $(3.667,5.667,7.667)$ & $(4.333,6.333,8.333)$ & $(5.667,7.667,9.333)$ \\
\hline
\end{tabular}

Table 5: The weighted fuzzy assessment matrix and the best assessment on each criteria

\begin{tabular}{|c|c|c|c|c|c|c|}
\hline Criteria & Defuzzified weight & Supplier A & Supplier B & Supplier C & Supplier D & The largest fuzzy number \\
\hline C1.1 & 0.052 & $(0.293,0.396,0.483)$ & $(0.121,0.224,0.327)$ & $(0.224,0.327,0.431)$ & $(0.259,0.362,0.448)$ & $(0.293,0.396,0.483)$ \\
\hline $\mathrm{C} 1.2$ & 0.052 & $(0.155,0.259,0.362)$ & $(0.293,0.396,0.483)$ & $(0.190,0.293,0.396)$ & $(0.327,0.431,0.500)$ & $(0.327,0.431,0.500)$ \\
\hline $\mathrm{C} 1.3$ & 0.073 & $(0.175,0.325,0.475)$ & $(0.225,0.375,0.525)$ & $(0.100,0.225,0.375)$ & $(0.375,0.525,0.650)$ & $(0.375,0.525,0.650)$ \\
\hline $\mathrm{C} 1.4$ & 0.022 & $(0.094,0.137,0.181)$ & $(0.065,0.109,0.152)$ & $(0.109,0.152,0.188)$ & $(0.094,0.137,0.174)$ & $(0.109,0.152,0.188)$ \\
\hline $\mathrm{C} 2.1$ & 0.053 & $(0.089,0.195,0.302)$ & $(0.195,0.302,0.409)$ & $(0.195,0.302,0.409)$ & $(0.302,0.409,0.498)$ & $(0.302,0.409,0.498)$ \\
\hline $\mathrm{C} 2.2$ & 0.062 & $(0.226,0.350,0.473)$ & $(0.391,0.514,0.596)$ & $(0.226,0.345,0.473)$ & $(0.391,0.514,0.596)$ & $(0.391,0.514,0.596)$ \\
\hline $\mathrm{C} 2.3$ & 0.095 & $(0.602,0.792,0.918)$ & $(0.158,0.348,0.538)$ & $(0.412,0.602,0.792)$ & $(0.602,0.792,0.918)$ & $(0.602,0.792,0.918)$ \\
\hline $\mathrm{C} 2.4$ & 0.042 & $(0.264,0.348,0.403)$ & $(0.070,0.153,0.236)$ & $(0.070,0.153,0.236)$ & $(0.125,0.209,0.292)$ & $(0.264,0.348,0.403)$ \\
\hline C3.1 & 0.062 & $(0.347,0.473,0.576)$ & $(0.226,0.350,0.473)$ & $(0.226,0.350,0.473)$ & $(0.309,0.432,0.535)$ & $(0.350,0.473,0.576)$ \\
\hline $\mathrm{C} 3.2$ & 0.072 & $(0.406,0.550,0.669)$ & $(0.215,0.359,0.502)$ & $(0.454,0.598,0.693)$ & $(0.311,0.454,0.598)$ & $(0.454,0.598,0.693)$ \\
\hline C3.3 & 0.115 & $(0.728,0.958,1.112)$ & $(0.345,0.575,0.805)$ & $(0.422,0.652,0.882)$ & $(0.652,0.882,1.073)$ & $(0.728,0.958,1.112)$ \\
\hline C3.4 & 0.053 & $(0.267,0.373,0.462)$ & $(0.124,0.231,0.338)$ & $(0.231,0.338,0.444)$ & $(0.373,0.480,0.533)$ & $(0.373,0.480,0.533)$ \\
\hline C3.5 & 0.063 & $(0.401,0.528,0.612)$ & $(0.106,0.232,0.359)$ & $(0.274,0.401,0.528)$ & $(0.401,0.528,0.612)$ & $(0.401,0.528,0.612)$ \\
\hline $\mathrm{C} 3.6$ & 0.073 & $(0.415,0.562,0.684)$ & $(0.171,0.318,0.464)$ & $(0.024,0.122,0.269)$ & $(0.415,0.562,0.684)$ & $(0.415,0.562,0.684)$ \\
\hline $\mathrm{C} 4.1$ & 0.033 & $(0.211,0.278,0.322)$ & $(0.144,0.211,0.278)$ & $(0.167,0.233,0.289)$ & $(0.100,0.167,0.233)$ & $(0.211,0.278,0.322)$ \\
\hline $\mathrm{C} 4.2$ & 0.043 & $(0.274,0.361,0.419)$ & $(0.058,0.130,0.217)$ & $(0.159,0.245,0.332)$ & $(0.245,0.332,0.404)$ & $(0.274,0.361,0.419)$ \\
\hline $\mathrm{C} 4.3$ & 0.063 & $(0.274,0.401,0.528)$ & $(0.190,0.317,0.443)$ & $(0.317,0.443,0.549)$ & $(0.148,0.274,0.401)$ & $(0.317,0.443,0.549)$ \\
\hline $\mathrm{C} 4.4$ & 0.032 & $(0.021,0.074,0.137)$ & $(0.116,0.180,0.243)$ & $(0.137,0.201,0.264)$ & $(0.180,0.243,0.296)$ & $(0.180,0.243,0.296)$ \\
\hline
\end{tabular}


Table 6: Regret matrix

\begin{tabular}{ccccc}
\hline Criteria & Supplier A & Supplier B & Supplier C & Supplier D \\
\hline C1.1 & 0 & 0.167 & 0.063 & 0.035 \\
C1.2 & 0.161 & 0.029 & 0.126 & 0 \\
C1.3 & 0.192 & 0.142 & 0.283 & 0 \\
C1.4 & 0.012 & 0.041 & 0 & 0.015 \\
C2.1 & 0.207 & 0.101 & 0.101 & 0 \\
C2.2 & 0.151 & 0 & 0.151 & 0 \\
C2.3 & 0 & 0.422 & 0.169 & 0 \\
C2.4 & 0 & 0.185 & 0.185 & 0.130 \\
C3.1 & 0 & 0.117 & 0.117 & 0.041 \\
C3.2 & 0.040 & 0.223 & 0 & 0.128 \\
C3.3 & 0 & 0.358 & 0.281 & 0.064 \\
C3.4 & 0.095 & 0.231 & 0.124 & 0 \\
C3.5 & 0 & 0.281 & 0.113 & 0 \\
C3.6 & 0 & 0.236 & 0.415 & 0 \\
C4.1 & 0 & 0.059 & 0.041 & 0.104 \\
C4.2 & 0 & 0.217 & 0.106 & 0.024 \\
C4.3 & 0.035 & 0.120 & 0 & 0.162 \\
C4.4 & 0.162 & 0.060 & 0.039 & 0 \\
\hline & & & &
\end{tabular}

Table 7: Sorted regret values and OWA weights

\begin{tabular}{cccccc}
\hline$\rho_{k}$ & Supplier A & Supplier B & Supplier C & Supplier D & OWA weight \\
\hline$\rho_{1}$ & 0.207 & 0.422 & 0.415 & 0.162 & 0.236 \\
$\rho_{2}$ & 0.192 & 0.358 & 0.283 & 0.130 & 0.098 \\
$\rho_{3}$ & 0.162 & 0.281 & 0.281 & 0.128 & 0.075 \\
$\rho_{4}$ & 0.161 & 0.236 & 0.185 & 0.104 & 0.063 \\
$\rho_{5}$ & 0.151 & 0.231 & 0.169 & 0.064 & 0.056 \\
$\rho_{6}$ & 0.095 & 0.223 & 0.151 & 0.041 & 0.050 \\
$\rho_{7}$ & 0.040 & 0.217 & 0.126 & 0.035 & 0.046 \\
$\rho_{8}$ & 0.035 & 0.185 & 0.124 & 0.024 & 0.043 \\
$\rho_{9}$ & 0.012 & 0.167 & 0.117 & 0.015 & 0.040 \\
$\rho_{10}$ & 0 & 0.142 & 0.113 & 0 & 0.038 \\
$\rho_{11}$ & 0 & 0.120 & 0.106 & 0 & 0.036 \\
$\rho_{12}$ & 0 & 0.117 & 0.101 & 0 & 0.035 \\
$\rho_{13}$ & 0 & 0.101 & 0.063 & 0 & 0.033 \\
$\rho_{14}$ & 0 & 0.060 & 0.041 & 0 & 0.032 \\
$\rho_{15}$ & 0 & 0.059 & 0.039 & 0 & 0.031 \\
$\rho_{16}$ & 0 & 0.041 & 0 & 0 & 0.030 \\
$\rho_{17}$ & 0 & 0.029 & 0 & 0 & 0.029 \\
$\rho_{18}$ & 0 & 0 & 0 & 0 & 0.028 \\
\hline & & & & & \\
\hline
\end{tabular}

Table 8: The effective regrets and the ranking results for four suppliers

\begin{tabular}{lccc}
\hline & Regret & The proposed model & The method in [49] \\
\hline Supplier A & 0.107 & 2 & 1 \\
Supplier B & 0.242 & 4 & 3 \\
Supplier C & 0.210 & 3 & 2 \\
Supplier D & 0.076 & 1 & 1 \\
\hline
\end{tabular}


decision makers, and the best choice is supplier D which has the best performance. From Table 8 , the effective regrets of supplier D and supplier A is 0.076 , and 0.107 respectively. According to these two regret values, the manager can easily make a clear choice to choose supplier D.

\section{Conclusion}

A good GSCM is important for reducing the environmental harm cased by industrial activities through the supply chain. The companies need to evaluate their own GSCM performance and select the best supplier. Therefore a good evaluation model plays an important part. In this paper, a novel fuzzy multi-criteria decision making method for GSCM is proposed. In the proposed decision-making method, the regret sense of decision-maker is taken into consideration, which improves the accuracy and reliability of decision making. Besides, instead of using the basic regret decision-making method, the fuzzy generalized regret decision-making method is proposed to obtain effective regret. The generalized regret decision making method based on OWA is used for certain decision-making environment in [55]. On this basic, the proposed method can be used to settle problems under fuzzy decision-making environment. Then the proposed method is implemented to the case about GSCM practices introduced in [49], as a result of which, a more accurate and clearer ranking result about green suppliers is obtained. A comparative analysis of the result verifies the effectiveness and feasibility of the proposed method in this paper. In the future research, the proposed method is expected to extend its applications. More multi-decision making problems in any other application background can be considered to resolve with this method.

\section{Acknowledgments}

The work is partially supported by National Natural Science Foundation of China (Program No. 61671384,61703338), the Seed Foundation of Innovation and Creation for Graduate Students in Northwestern Polytechnical University (Program No. ZZ2017126).

\section{Conflict of interests}

The authors declare that there is no conflict of interests.

\section{Bibliography}

[1] Andiç E., Yurt Ö., and Baltacığlu Baltacıŏlu T.(2012); Green supply chains: Efforts and potential applications for the turkish market, Resources Conservation \& Recycling, 58, 50-68, 2012.

[2] Azevedo S. G., Carvalho H., and Machado V.C. (2011); The influence of green practices on supply chain performance: A case study approach, Transportation Research Part E Logistics \& Transportation Review, 47(6), 850-871, 2011.

[3] Beamon B. M. (1998); Supply chain design and analysis: Models and methods, International Journal of Production Economics, 55(3), 281-294, 1998.

[4] Bell D. E. (1980); Regret in decision making under uncertainty, 30, Informs, 1982. 
[5] Büyüközkan G. and Çifçi G. (2011); A novel fuzzy multi-criteria decision framework for sustainable supplier selection with incomplete information, Computers in Industry, 62(2), 164-174, 2011.

[6] Chan H. K., He H., and Wang W. Y. C. (2012); Green marketing and its impact on supply chain management in industrial markets, Industrial Marketing Management, 41(4), 557-562, 2012 .

[7] Chien M. K. and Shih L. H. (2007); An empirical study of the implementation of green supply chain management practices in the electrical and electronic industry and their relation to organizational performances, International Journal of Environmental Science \& Technology, 4(3), 383-394, 2007.

[8] Chao X., Peng Y., and Kou G. (2016); A similarity measure-based optimization model for group decision making with multiplicative and fuzzy preference relations, International Journal of Computers Communications \& Control, 12(1), 26-40, 2016.

[9] Dou Y., Zhu Q., and Sarkis J. (2014); Evaluating green supplier development programs with a grey-analytical network process-based methodology, European Journal of Operational Research, 233(2), 420-431, 2014.

[10] Deng X., Xiao F., and Deng Y. (2017); An improved distance-based total uncertainty measure in belief function theory, Applied Intelligence, 46(4), 898-915, 2017.

[11] Deng X. and Jiang W. (2018); Dependence assessment in human reliability analysis using an evidential network approach extended by belief rules and uncertainty measures, Annals of Nuclear Energy, 117, 183-193, 2018.

[12] Deng X. (2018); Analyzing the monotonicity of belief interval based uncertainty measures in belief function theory, International Journal of Intelligent Systems, Published online, doi: 10.1002/int.21999, 2018.

[13] Deng X., Han D., Dezert J., Deng Y., and Yu S. (2016); Evidence combination from an evolutionary game theory perspective, IEEE Transactions on Cybernetics, 46(9), 2070-2082, 2016.

[14] Deng X. and Jiang W. (2018); An evidential axiomatic design approach for decision making using the evaluation of belief structure satisfaction to uncertain target values, International Journal of Intelligent Systems, 33(1), 15-32, 2018.

[15] Deza M. M. and Deza E. (2009); Encyclopedia of distances, Encyclopedia of Distances, 24, 1-583, Springer, 2009.

[16] Dzitac I. (2015); The fuzzification of classical structures: A general view, International Journal of Computers Communications \& Control, 10(6), 772-778, 2015.

[17] Eltayeb T. K.,Zailani S., and Ramayah T. (2011); Green supply chain initiatives among certified companies in malaysia and environmental sustainability: Investigating the outcomes, Resources Conservation \& Recycling, 55(5), 495-506, 2011.

[18] ElSayed A., Kongar E., and Gupta S. M. (2015); Fuzzy linear physical programming for multiple criteria decision-making under uncertainty, International Journal of Computers Communications \& Control, 11(1), 26-38, 2015. 
[19] Filiz-Ozbay E. and Ozbay E. Y. (2007); Auctions with anticipated regret: Theory and experiment, American Economic Review, 97(4), 1407-1418, 2007.

[20] Govindan K., Kadziński M., and Sivakumar R. (2017); Application of a novel prometheebased method for construction of a group compromise ranking to prioritization of green suppliers in food supply chain, Omega, 71, 129-145, 2017.

[21] Ghorabaee M.K, Amiri M., and Zavadskas E. K., Antucheviciene and J. (2017); Supplier evaluation and selection in fuzzy environments: a review of madm approaches, Economic research-Ekonomska istraživanja, 30(1), 1073-1118, 2017.

[22] Ghorabaee M. K. , Zavadskas E. K., Amiri M., and Turskis Z. (2016); Extended edas method for fuzzy multi-criteria decision-making: an application to supplier selection, International Journal of Computers Communications \& Control,11(3), 358-371, 2016.

[23] Gencer C. and Gürpinar D. (2007); Analytic network process in supplier selection: A case study in an electronic firm, Applied Mathematical Modelling, 31(11), 2475-2486, 2007.

[24] GrecoS., Kadziński M., Mousseau V., and Słowiński R. (2012); Robust ordinal regression for multiple criteria group decision: Uta-group and utadis-group, Decision Support Systems, 52(3), 549-561, 2012.

[25] Handfield R., WaltonS. V., Sroufe R., and Melnyk S. A. (2002); Applying environmental criteria to supplier assessment: A study in the application of the analytical hierarchy process, European Journal of Operational Research, 141(1), 70-87, 2002.

[26] Humphreys P. K., Wong Y. K., and Chan F. T. S. (2003); Integrating environmental criteria into the supplier selection process, Journal of Materials Processing Technology, 138(1), 349356, 2003.

[27] He Z. and Jiang W. (2018); An evidential dynamical model to predict the interference effect of categorization on decision making, Knowledge-Based Systems, p. Published on line. Doi: 10.1016/j.knosys.2018.03.014, 2018.

[28] HervaniA. A., Helms M. M., and Sarkis J. (2005); Performance measurement for green supply chain management, Benchmarking, 12(4), 330-353, 2005.

[29] Hsieh C. H. and Chen S. H. (1999); Model and algorithm of fuzzy product positioning, Information Sciences, 121(1), 61-82, 1999.

[30] Igarashi M., Boer L. D., and Fet A. M.(2013); What is required for greener supplier selection? A literature review and conceptual model development, Journal of Purchasing 85 Supply Management, 19(4), 247-263, 2013.

[31] Jabbour C. J. C. (2015); Green human resource management and green supply chain management: Linking two emerging agendas, Journal of Cleaner Production, 112, 1824-1833, 2015 .

[32] Jiang W. and Wei B. (2018); Intuitionistic fuzzy evidential power aggregation operator and its application in multiple criteria decision-making, International Journal of Systems Science, 49(3), 582-594, 2018.

[33] Jiang W., Chang Y., and Wang S. (2017); A method to identify the incomplete framework of discernment in evidence theory, Mathematical Problems in Engineering, 2017, Article ID $7635972,2017$. 
[34] Jiang W. and Hu W. (2018); An improved soft likelihood function for Dempster-Shafer belief structures, International Journal of Intelligent Systems, Published on line. Doi: 10.1002/int.219809, 2018.

[35] Jiang W. and Wang S. (2017); An uncertainty measure for interval-valued evidences, International Journal of Computers Communications \& Control, 12(5), 631-644, 2017.

[36] Jiang W., Wei B., Liu X., Li X., and Zheng H. (2018); Intuitionistic fuzzy power aggregation operator based on entropy and its application in decision making, International Journal of Intelligent Systems, 33(1), 49-67, 2018.

[37] Kannan D. and Jabbour C. J. C. (2014); Suppliers based on gscm practices: Using fuzzy topsis applied to a brazilian electronics company, European Journal of Operational Research, 233(2), 432-447, 2014.

[38] Kaplinski O., Peldschus F., and Tupenaite L. (2014); Development of mcdm methods-in honour of professor edmundas kazimieras zavadskas on the occasion of his 70th birthday, International Journal of Computers Communications \& Control, 9(3), 305-312, 2014.

[39] Kannan D., Khodaverdi R., Olfat L., Jafarian A., and Diabat A. (2013); Integrated fuzzy multi criteria decision making method and multi-objective programming approach for supplier selection and order allocation in a green supply chain, Journal of Cleaner Production, 47(9), 355-367, 2013.

[40] Kusi-Sarpong S., Sarkis J., and Wang X. (2016); Assessing green supply chain practices in the ghanaian mining industry: A framework and evaluation, International Journal of Production Economics, 181, 325-341, 2016.

[41] Kaufmann A. (1987); Introduction to fuzzy arithmetic: Theory and applications, International Journal of Approximate Reasoning, 1(1), 141-143, 1987.

[42] Loomes G. and Sugden R. (1982); Regret theory: An alternative theory of rational choice under uncertainty, Economic Journal, 92(368), 805-824, 1982.

[43] Liang W., He J., Wang S., Yang L., and Chen F. (2018) Improved cluster collaboration algorithm based on wolf pack behavior, Cluster Computing, Published online, doi: $10.1007 / \mathrm{s} 10586-018-1891-\mathrm{y}, 2018$.

[44] Liu W., Liu H. B., and Li L. L. (2017); A multiple attribute group decision making method based on 2-D uncertain linguistic weighted heronian mean aggregation operator, International Journal of Computers Communications \& Control, 12(2), 254-264, 2017.

[45] Mo H. and Deng Y. (2016); A new aggregating operator in linguistic decision making based on D numbers, International Journal of Uncertainty, Fuzziness and Knowledge-Based Systems, 24(6), 831-846, 2016.

[46] Merigo J. M. and Casanovas M. (2010); The fuzzy generalized owa operator and its application in strategic decision making, Cybernetics and Systems: An International Journal, 41(5), 359-370, 2010.

[47] O'Hagan M. (1988) Aggregating template or rule antecedents in real-time expert systems with fuzzy set logic, Signals, Systems and Computers, 1988. IEEE Conference TwentySecond Asilomar, 2, 681-689, 1988. 
[48] Rajendran K., S., Sarkis J.,Murugesan and P. (2015); Multi criteria decision making approaches for green supplier evaluation and selection: A literature review, Journal of Cleaner Production, 98, 66-83, 2015.

[49] Sari K. (2017); A novel multi-criteria decision framework for evalutaing green supply chain management practices, Computers \& Industrial Engineering, 105, 338-347, 2017.

[50] Walton S. V., Handfield R. B., and Melnyk S. A. (1998); The green supply chain: Integrating suppliers into environmental management processes, Journal of Supply Chain Management, 34(1), 2-11, 1998.

[51] Xiao F. (2017); An improved method for combining conflicting evidences based on the similarity measure and belief function entropy, International Journal of Fuzzy Systems,Published online, DOI: 10.1007/s40815-017-0436-5, 2017.

[52] Xiao F. (2016); An intelligent complex event processing with D numbers under fuzzy environment, Mathematical Problems in Engineering, 2016, p. Article ID: 3713518, 2016.

[53] Xu S., Jiang W., Deng X., and Shou Y. (2018); A modified physarum-inspired model for the user equilibrium traffic assignment problem, Applied Mathematical Modelling, 55, 340-353, 2018.

[54] Xu H. and Deng Y. (2018); Dependent evidence combination based on shearman coefficient and pearson coefficient, IEEE Access, 6, 11634-11640, 2018.

[55] Yager R. R. (2017); Generalized regret based decision making, Engineering Applications of Artificial Intelligence, 65, 400-405, 2017.

[56] Yager R. R. (1996); Quantifier guided aggregation using owa operators, International Journal of Intelligent Systems, 11(1), 49-73, 1996.

[57] Yager R. R. (1998); On ordered weighted averaging aggregation operators in multicriteria decisionmaking, IEEE Transactions on systems, Man, and Cybernetics, 18(1), 183-190, 1988 .

[58] Zadeh L. A. (1965); Fuzzy sets, Information \& Control, 8(3), 338-353, 1965.

[59] Zhu Q., Sarkis J., and Lai K. H.(2012); Green supply chain management innovation diffusion and its relationship to organizational improvement: An ecological modernization perspective, Journal of Engineering and Technology Management, 29(1), 168-185, 2012.

[60] Zhu Q., Sarkis J., and Lai K. H. (2008); Confirmation of a measurement model for green supply chain management practices implementation, International Journal of Production Economics, 111(2), 261-273, 2008.

[61] Zhou X., Hu Y., Deng Y., Chan F. T. S., and Ishizaka A. (2018); A DEMATEL-Based completion method for incomplete pairwise comparison matrix in AHP, Annals of Operations Research, Published online, doi: 10.1007/s10479-018-2769-3, 2018.

[62] Zheng X. and Deng Y. (2018); Dependence assessment in human reliability analysis based on evidence credibility decay model and iowa operator, Annals of Nuclear Energy, 112, 673-684, 2018.

[63] Zheng H., Deng Y., and Hu Y. (2017); Fuzzy evidential influence diagram and its evaluation algorithm, Knowledge-Based Systems, 131, 28-45, 2017. 